\title{
DEVELOPMENT OF AN EXPERT SYSTEM FOR THE DETERMINATION OF THE SPAN OF CONTROL OF THE CONSTRUCTION FOREMAN
}

\author{
Igal M. Shohet, M.Sc. \\ National Building Research Institute \\ Technion, Israel. \\ Alexander Laufer, Ph.D. \\ National Building Research Institute \\ Technion, Israel.
}

\begin{abstract}
The development of expert systems in construction management has been widely implemented to deal with heuristics involved in construction decisions. The role of the construction foreman, particularly his span of control (number of subordinates) has not received the degree of attention it deserves in research and in expert systems. Situational analysis offers a systematic way to solve questions concerning span of control and their relationships to context variables effects on crew size. An expert system currently in development is based on the situational analysis approach. Using the system enables determination of a suitable span of control for a given set of context variables.
\end{abstract}

Keywords: Construction management; crew size; span of control; situational analysis; expert system.

\section{INTRODUCTION}

The role of the construction foreman, particularly his span of control (number of subordinates) has not been systematically studied. Determining SOC (Span of Control) depends on many context variables (e.g. job experience of foreman and formworkers, professional training, job complexity, quality of design and planning). In practice determining the SOC is an intuitive process, based on individual experience which does not rigorously take into account the complete array of considerations on which SOC dependent. A systematic approach for determining SOC might be done through situational analysis of the foreman's span of control (Laufer and Shohet 1991).

This paper presents an empirical study based on structured interviews and field observations on the SOC of the formworkers' foreman. Based on this study, an expert system for determining the crew size of formworkers is at an advanced stage of development. The expert system is used as a bridge between two studies: the preliminary study which established the individual components of the model (i.e. influence of foreman's training on SOC) and the future study which will examine and validate the model on which the expert system is based. The knowledge base of the expert system is represented with frames which are suitable structures for a complex and rich representation of knowledge (Adeli 1988). The inference mechanism processes forward chaining rules which work in two main stages:

1. Calculation of a preliminary composite multiplier and crew size (details proceded).

2. Refinement of the SOC according to technical feasibilities and time constraints (e.g. natural construction work sector can be divided into segments suitable for acceptable crew size).

\section{RESEARCH SCOPE AND METHOD}

An elaborate preliminary research was conducted which focused on crew management and crew performance at the construction site. The study concentrated on questions of organization, planning and control, productivity, safety, motivation and 
others. A detailed description of the research is presented in [Laufer \& Shohet, 1988; Laufer \& Shohet 1991; Shohet \& Laufer 1991].

The data were obtained through structured interviews following a format of a questionnaire described in the following section, conducted on-site in Texas and in Israel, and through structured observations in Israel based on the work sampling method, which were taken as a reliable productivity indicator (Handa and Abdalla 1989).

Data regarding the various factors affecting the foreman's Span of Control were also obtained through interviews with foremen. The factors and situations on which questions were asked were culled from the literature outside construction and from construction literature (e.g. Borcherding 1977; Hinze and Kuchenmeister 1981; Levitt et al. 1984; Samelson 1977). Another source of data was from test interviews conducted during a preliminary study carried out in Texas and in Israel. The data reported here are based mainly on the Israeli data base which was the main source for the parameters of the expert system.

The following data are highlights of interviews with site managers and foremen.

- Number of construction sites investigated - 32 .

- Mean crew size of formworkers - 9.4.

- Percentage of crews with an assistant foreman - 93.0\%.

- Mean percentage of time invested in managerial activities by the assistant foreman $-42.7 \%$.

- Mean length of formworkers' experience in the trade -8.2 years.

- Percentage of formally trained carpenters $-7.6 \%$.

The underlining assumption to the questions of variability of SOC is that the size of the crew affects performance level. In the following section this assumption is examined.

\section{EFFECT OF CREW SIZE ON PERFORMANCE}

Two process-oriented yardsticks were employed to measure crew performance: (1) Work sampling; (2) Safety sampling. The work samples were classified in three categories according to Parker and Oglesby (1979): (a) Effective work; (b) Essential contributory work and (c) Ineffective work. The mean values obtained for all sites for the three categories were: Effective work - 30.3\%; Essential contributory work - 30.9\%; Ineffective work $-38.9 \%$.

The safety sampling followed a similar pattern to work sampling, except that the observed work was classified in work safety categories:

a. Unsafe act/situation: Describes hazardous use of tools or equipment, or hasty execution of work in an unsafe place or under unsafe conditions. The mean result of the sampling was $5 \%$.

b. Safe act/situation - that category includes activities performed without risks or hazards to the formworker or others, and in safe surrounding. The mean result of the sampling was $95 \%$.

For the analysis of crew size on its performance, the work sampling was divided into small size crews of up to 8 workers and large crews with 9 workers and up. Small crews registered $33 \%$ of effective work and large crews a $27 \%$ share of effective work. A $T$-test showed that this difference is significant at $\alpha<0.05$ (where $\alpha$ is the level of significance of the difference).

To analyze safety performance, twelve very small crews comprising up to six workers were compared with seven large crews of fifteen workers or more. The percentage of unsafe acts/situation of the small crews rated at $3 \%$, compared to $7.6 \%$ of the large crews, representing a noteworthy difference at $\alpha<0.05$. These results show a significant effect of the crew size on its performance. 


\section{SITUATIONAL ANALYSIS OF SOC}

SOC is defined as the number of subordinates reporting to a given supervisor. Particular attention is devoted to SOC efficacy of the first line supervisor. Previous works stress the importance of limiting the size of the crew under a supervisor [Lawler and Hackman 1975; Ouchi and Dowling 1974; Steiglitz 1962; Woodward 1965]. These works support the use of situational analyses of the factors that govern the unit's performance such as similarity of tasks, managerial support the unit leader gets from
his lower echelons and workers' motivation.

\section{STRUCTURE OF THE QUESTIONNAIRE}

This part of the study investigated quantitatively the effects of nine significant factors on the SOC. These are factors which were found in a previous study [Laufer and Shohet 1991], to be among the most important. Data were obtained by means of structured interviews of thirty-two foremen based on a questionnaire. The questionnaire consisted of eighteen questions relating to the nine factors. Each of the nine factors were presented in two extreme situations: one "fostering" the extension of the foreman's SOC, and the other "impeding" the foreman's SOC (18 total situations). For each situation, the foreman was asked to determine the maximum SOC, assuming that all other eight factors were in a "middle situation". The term "middle situation" was defined as a state half way between the two given extreme situations. The maximum SOC was defined as the number of workers, which if exceeded in a given circumstance, would diminish the control effectiveness of the foreman. The following
nine factors were presented to the interviewee:

\section{Carpenters' motivation}

Fostering - A group unsupervised for 2 hours will continue to perform well.

2. Carpenters' training

Fostering - Formally trained, read blueprints.

3. Carpenters' experience

Fostering - 5 years or more working in the trade.

Impeding - Less than 1 year.

4. Foreman's managerial training and experience as foreman

Fostering - Formal training with 5 years experience.

Impeding - No training, less than 1 year as foreman.

5. Foreman's managerial style

Fostering - Candid relations between foreman and his subordinates - he is

"people" oriented.

6. Foreman's assistant Formal relations between foreman and his subordinates - he is "task"
oriented.

Fostering - Appointed and participates manually less than $50 \%$ of the time.

Impeding - No assistant appointed.

7. Quality of information provided to foreman

Fostering - Blueprints and construction plans are detailed, complete and on time.

Impeding - Blueprints and construction plans are general, incomplete and late.

8. Work complexity

Fostering - Very common project with simple and routine operations.

Impeding - Non-repetitive, many trades, complex operations.

9. Dispersal of work locations between the crew members

Fostering - Less than 30 yards apart.

Impeding - Distances greater than 60 yards. 


\section{SITUATIONAL RANGES AND MULTIPLIERS}

A variable, termed situational range (SR), was defined for each factor, as the mean difference between the SOCs in the two extreme situations (fostering and impeding), as assessed by the foremen interviewed. Values of the SOCs in each of the situations, and their SR for the nine factors, are presented in table 1.

Other variables, termed "situational multipliers" (SM), were developed to quantitatively express the effect of each factor in fostering and impeding situations. An SM is defined as the mean of the ratio of a situational SOC to the overall mean SOC, as shown below in equations 1 and 2 .

$$
\begin{aligned}
& \text { FSM }= \frac{\sum_{i=1}^{n} \frac{\operatorname{SOC}(F)}{\overline{S O C}}}{n} \\
& \text { ISM }=\frac{\sum_{i=1}^{n} \frac{\operatorname{SOC}(I)}{\overline{S O C}}}{n}
\end{aligned}
$$

where:

FSM - Fostering Situational Multiplier

ISM - Impeding Situational Multiplier

$\mathrm{SOC}(\mathrm{F})-\mathrm{SOC}$ in fostering situation

SOC(I) - SOC in impeding situation

$\overline{\mathrm{SOC}}$ - Overall mean SOC

j - Participant

$\mathrm{n}$ - numer of participants.

Values for the multipliers of the nine factors are presented in table 2.

Using the multipliers defined above, one $\mathrm{CAB}$ predict how enlarging or reducing the crew size, can be done without detrimental effect on the foreman's ability to control the work. For example, if the multiplier for foreman's assistantship is 1.5 , the addition of an assistant enables enlargement of the SOC of the foreman by $50 \%$, compared with a middle situation.

\section{Main findings in table 1 are:}

1. The two highest SOC in fostering situations are for foreman's assistantship and training: 20.5 and 19.2 respectively.

2. The two lowest SOC in impeding situation are formworkers' experience and motivation: 8.7 and 8.8 respectively.

3. The highest situational range is for foreman's training -10.3 , indicating the wide variability of the SOC due to differences in that factor.

Main findings in table 2 are:

1. The highest FSM is for foreman's assistantship, FSM $=1.5$, while the ISM $=0.9$, with $\operatorname{SOC}(\mathrm{I})=12.7$ which is close to the overall mean (13.5).

2. The second highest FSM is for foreman's training where FSM $=1.4$. The ISM for this factor equals 0.7 .

3. The lowest ISM is for formworkers' experience where ISM $=0.6$.

4. The other formworkers' characteristics (motivation and training) have a similar significant effect in fostering and in impeding situations FSM and ISM for both of them are 1.3 and 0.7 respectively. 
Table 1: Span of Control in Fostering and in Impeding Situations, and in Situational Range

\begin{tabular}{|c|c|c|c|c|}
\hline \multicolumn{2}{|r|}{ FACTOR } & FOSTERING & IMPEDING & $\begin{array}{c}\text { Situational } \\
\text { range }\end{array}$ \\
\hline $\begin{array}{l}\text { Formworkers' } \\
\text { characteristics }\end{array}$ & $\begin{array}{l}\text { Formworkers' motivation } \\
\text { Formworkers' training } \\
\text { Formworkers' experience }\end{array}$ & $\begin{array}{l}17.2 \\
17.4 \\
16.7\end{array}$ & $\begin{array}{l}8.8 \\
9.7 \\
8.7\end{array}$ & $\begin{array}{l}8.4 \\
7.7 \\
8.0\end{array}$ \\
\hline $\begin{array}{l}\text { Foreman's } \\
\text { characteristics }\end{array}$ & $\begin{array}{l}\text { Foreman's training } \\
\text { Foreman's managerial } \\
\text { style } \\
\text { Foreman's assistantship }\end{array}$ & $\begin{array}{l}19.2 \\
16.1 \\
20.5\end{array}$ & $\begin{array}{r}8.9 \\
9.9 \\
12.7\end{array}$ & $\begin{array}{l}10.3 \\
6.2 \\
7.8\end{array}$ \\
\hline $\begin{array}{l}\text { Project's } \\
\text { characteristics }\end{array}$ & $\begin{array}{l}\text { Quality of information } \\
\text { Work complexity } \\
\text { Dispersal of work } \\
\text { locations }\end{array}$ & $\begin{array}{l}15.4 \\
17.5 \\
15.6\end{array}$ & $\begin{array}{l}10.3 \\
11.6 \\
12.4\end{array}$ & $\begin{array}{l}5.1 \\
5.9 \\
3.2\end{array}$ \\
\hline Mean situ & lational SOC & 17.3 & 10.3 & 7.9 \\
\hline Overall $\mathrm{m}$ & gean (SOC) & & & \\
\hline
\end{tabular}

Table 2: Situational multipliers

\begin{tabular}{|c|c|c|c|}
\hline \multicolumn{2}{|c|}{ FACTOR } & FOSTERING & IMPEDING \\
\hline $\begin{array}{l}\text { Formworkers' } \\
\text { characteristics }\end{array}$ & $\begin{array}{l}\text { Formworkers' motivation } \\
\text { Formworkers' training } \\
\text { Formworkers' experience }\end{array}$ & $\begin{array}{r}1.3 \\
7 \\
1.3 \\
1.2\end{array}$ & $\begin{array}{l}0.7 \\
0.7 \\
0.6\end{array}$ \\
\hline $\begin{array}{l}\text { Foreman's } \\
\text { characteristics }\end{array}$ & $\begin{array}{l}\text { Foremen's training } \\
\text { Foreman's manager al } \\
\text { style } \\
\text { Foreman's assistartship }\end{array}$ & $\begin{array}{l}1.4 \\
1.2 \\
1.5\end{array}$ & $\begin{array}{l}0.7 \\
0.7 \\
0.9\end{array}$ \\
\hline $\begin{array}{l}\text { Project's } \\
\text { characteristics }\end{array}$ & $\begin{array}{l}\text { Quality of information } \\
\text { Work complexity } \\
\text { Dispersal of work } \\
\text { locations }\end{array}$ & $\begin{array}{l}1.1 \\
1.3 \\
1.2\end{array}$ & $\begin{array}{l}0.8 \\
0.9 \\
0.9\end{array}$ \\
\hline Mean si & tional multiplier & 1.3 & 0.8 \\
\hline
\end{tabular}




\section{THE EXPERT SYSTEM}

The purposes of the system described are: (a) to examine the use of the situational analysis approach to select a suitable organizational scheme (in cases where constraints of time and technical feasibility do not prevent it), (2) to determine the crew size and other organizational parameters (e.g. foreman assistantship).

\section{THE KNOWLEDGE BASE}

The knowledge base consists of facts and rules. The facts arranged by means of frames, including four categories in the top level (Table 3): (1) Project characteristics; (2) Foreman characteristics; (3) Formworkers' characteristics; (4) Incentive programs. Each frame includes generic data in predefined slots. Some slots represent parameters of the project, others represent output variables and some are processing variables being used during a consultation session.

The first frame has four children frames: (1.1) Residential one-storey; (1.2) Residential multistory; (1.3) Non-residential buildings; (1.4) Industrial facilities. Each frame inherits all the slots of the "parent" frame (project characteristics) and also include several exclusive identical slots for the specific type of project. The frame knowledge representation was found suitable to organize knowledge which is analyzed by categories.

The inference engine process rules in two main phases:

1. Calculation of three main situational multipliers, representing the expected effects of its factors on the SOC, calculation of a composite multiplier (Figs. 2 and 3 , and equations 3 and 4), preliminary crew size, and composite crew size. The approach for the calculation of multipliers is adopted from [Neil 1982], which relates to productivity estimating. The validity of this approach to SOC will be examined in an extensive field study in the future.

$$
\begin{aligned}
\text { ICM } & =\frac{1}{1+\Sigma \text { Impeding adjustment factor }} \\
\text { FCM } & =1+\Sigma \text { Fostering adjustment factor }
\end{aligned}
$$

where: $\quad \mathrm{ICM}=$ Impeding composite Multiplier.

FCM $=$ Fostering Composite Multiplier.

Impeding Adjustment Factor $=1$-ISM.

Fostering Adjustment Factor $=$ FSM-1.

Preliminary crew size is calculated according to overall time constraints in cases where duration of construction formwork is predetermined, as shown in equation (5), and when not predetermined, according to the company's norms. We used, for company's norm, the mean crew size in the sample - 10 [Laufer and Shohet 1988].

$$
\mathrm{PCS}=\frac{\mathrm{Q} * W}{\mathrm{D} * \mathrm{~h}}
$$

where: $\quad$ PCS $=$ Preliminary Crew Size.

$\mathrm{Q}=$ Total area of formwork [sq.m].

$\mathrm{W}=$ Work Pace [hr/sq.m].

$\mathrm{D}=$ Planned duration of construction formwork [month].

$\mathrm{h}=$ Total amount of formworkers' hours in a month.

2. Refinement of the SOC according to several complementary context variables which are not included in the first stage, and adaptation of an organizational scheme, according to the following approaches:

2.1. A single large crew; large SOC with correspondingly lower productivity.

2.2. Sub-dividing sector into two segments, each manned by a smaller crew with its own foreman. The expected productivity will be high, duration of work short, but managerial overhead expense will be greater. There will also be need for coordination between the two foremen. 
Table 3 : Structure of the Frames

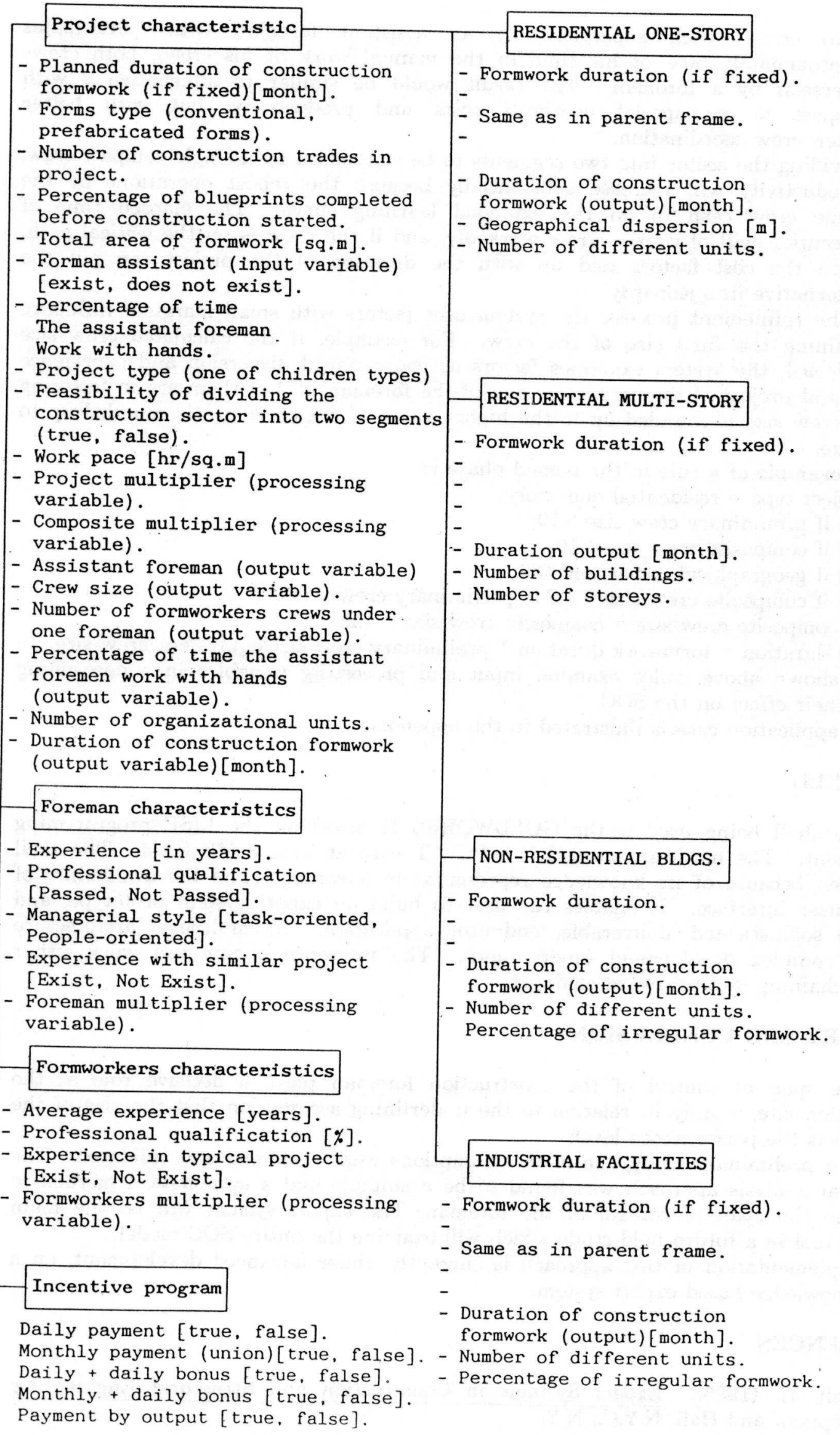


2.3. Two crews, each supervised by an assistant foreman (who participates approximately $50 \%$ of his time in the manual work of his crew), both crews overseen by a foreman. The result would be similar to alternative 2 with respect to managerial overhead costs and productivity, but with better inter-crew coordination.

2.4. Dividing the sector into two segments to be worked on by a single compact crew. Productivity will increase substantially because the repeat operations by the same crew cash in on the extended learning curve. The elapsed time of execution will of course, grow markedly, and if the crew is on the critical path, then the cost factors tied up with the duration of the project can put the alternative into jeopardy.

In the refinement process, the system uses factors with small marginal influence in determining the final size of the crew. For example, if the calculated crew size accepted is 9.4 , the system examines factors as geographical dispersion and experience in the typical project of the carpenters and of the foreman, if 2 of them are in fostering situation crew size is rounded up to the higher value, if not crew size is rounded up to lower value.

An example of a rule in the second phase is:

1. If project type $=$ residential one-story;

- and if preliminary crew size $>10$;

- and if composite crew size $>10$;

- and if geographical dispersion $<30$;

- and if composite crew size ${ }^{*} 1.2>$ preliminary crew size;

then composite crew size $=$ composite crew size $* 1.2$;

- and duration $=$ formwork duration $*$ preliminary crew size/equivalent crew size.

As shown above, rules examine input and processing variables in a descending order of their effect on the SOC.

An application case is illustrated in the appendix.

\section{THE SHELL}

The shell being used is the GOLDWORKS II based on the LISP programming environment. The hardware needed is a PC-AT with at least $8 \mathrm{MB}$ RAM. The shell was chosen because of its knowledge representation advantages and the availability of friendly user interface. It enables the user to build an expert system prototype, and introduce sophisticated, deliverable, end-user application. Its multilevel architecture provides complex development environment. The inference engine can work either forward chaining and backward chaining.

\section{SUMMARY AND CONCLUSIONS}

The span of control of the construction foreman plays a decisive role at the construction site, mainly in relation to the underlining assumption that the size of the crew affects the performance level.

In a preliminary study, the main assumptions were examined and validated. The situational analysis approach was found to be a suitable and a systematical method to determine the span of control of the foreman. The expert system will be the main research tool in a future field study which will examine the entire SOC model.

Implementation of this approach is currently under advanced development, on a frame knowledge based expert system.

\section{REFERENCES}

1) Adeli, H. (1988). Expert Systems in Construction and Structural Engineering, Chapman and Hall, N.Y.C., N.Y. 
3) Handa, V.K. and Abdalla, O. (1989). "Forecasting Productivity by Work Sampling". Construction Management and Economics, 7, 19-18.

4) Hinze, J. and Kuchenmeister, K. (1981). "Productive Foreman Characteristics". J. of Constr. Engrg. Mgmt., ASCE, 107, pp. 627-639.

5) Laufer, A. and Shohet, I.M. (1988). "Factors Affecting the Size of the Carpenters Crew". Technical Report, Building Research Station, Technion, Haifa, Israel.

6) Laufer, A. and Shohet, I.M. (1991). "Span of Control of the Construction Foreman: A Situational Analysis". J. Constr. Engrg. Mgmt., ASCE, 117(1), pp. 90-205.

7) Levitt, R.E., Samelson, N.M., Bretxa, J., Mummy, G., Waugh, L. (1984).

"Evaluation of the Line Foreman Safety Training Course". Technical Report, Department of Civil Engineering, Stanford University, Stanford, California.

8) Neil, J.M. (1982). Construction Cost Estimating to Project Control, Prentice Hall, Inc., Englewood Cliffs, NJ.

9) Shohet, I.M. and Laufer, A. (1991). "What does the Construction Foreman Do?". Construction Management and Economics, in press.

10) Ouchi, W.G. and Dowling, J.B. (1974). "Defining the Span of Control". Administrative Science Quarterly, 357-365.

11) Parker, H.W., Oglesby, C.H. (1972). Methods Improvement for Construction Managers, McGraw Hill Book Company, New York, N.Y.

12) Porter, L.W., Lawler, E.E. and Hackman, J.R. (1975). Behavior in Organizations, McGraw Hill, N.Y.C., N.Y.

13) Samelson, N.M. (1977). "The Effect of Foreman on Safety in Construction". Technical Report, Department of Civil Engineering, Stanford University, Stanford, California.

14) Steiglitz, H. (1962). "Optimizing Span of Control". Management Record, 24(9), 25-29.

15) Woodward, J. (1965). Industrial Organization: Theory and Practice, Oxford Univ. Press, London.

\section{APPENDIX - APPLICATION CASE}

\section{Project characteristics}

Planned duration of construction formwork $=6$ months

Forms type $=$ conventional

Number of construction trades $=20$

Total area of formwork $=18.000 \mathrm{sq} \cdot \mathrm{m}$

Percentage of blueprint completed before beginning of construction $=75$.

Foreman assistant $=$ exists

Percentage of time the assistant foreman works with hands $=50$

Project type $=$ residential one story

Number of construction sectors $=30$

Feasibility of dividing the construction sector into two segments $=$ true 
Geographical dispersion (farthest distance between units) $=100 \mathrm{~m}$

Number of different units $=0$

Foreman's characteristics

Experience $=4$ years

Professional qualification $=$ passed

Managerial style $=$ task oriented

Experience with similar project $=$ exists

Formworkers' characteristics

Average experience $=6$ years

Percentage of formworkers with professional qualification $=40$ percent of formworkers Experience of majority of formworkers with similar project $=$ exist

\section{Incentive program}

$\overline{\text { Monthly payment }}=$ true

Monthly payment $=$ false

Daily + daily bonus $=$ false

Monthly + daily bonus = false

Payment by output $=$ false

In phase I the following variables are calculated:

Project multiplier $=1.0$

Foreman multiplier $=0.9$

Formworkers multiplier $=1.15$

Composite multiplier $=1.05$

Preliminary crew size $=15$

Composite crew size $=10.5$

In phase II, two main solutions are examined: one crew with a large SOC (Crew size $=14$ ), and a second solution composed of 2 crews, each withan assistant foreman. Based on the situational analysis the solution recommended is:

Number of crews $=2$

Crew size $=8$

Number of assistant foreman $=2$

Number of organizational units $=1$

Percentage of time the assistant foreman works with hands $=25 \%$

Duration $=5.8$ months 


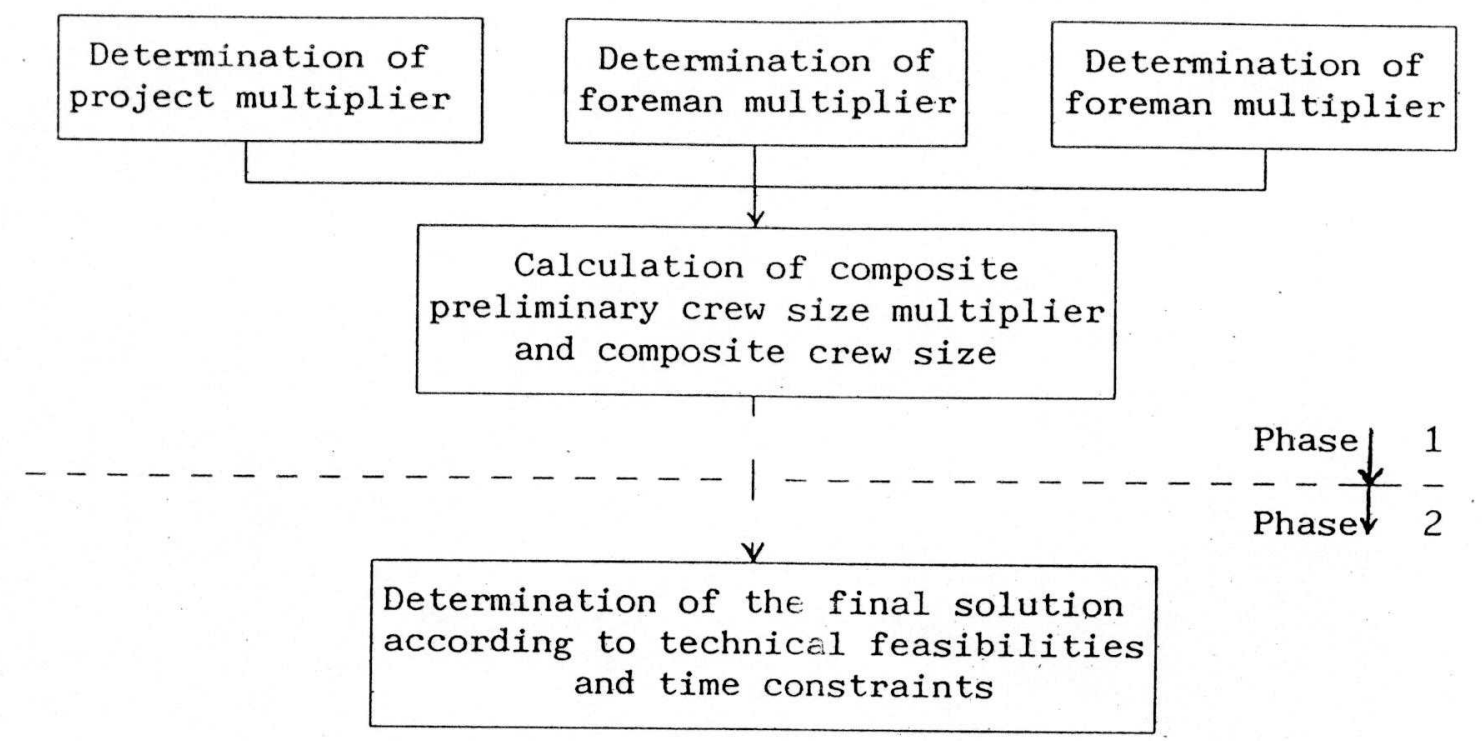

Fig 1: Schematic chart of the inference mechanism.

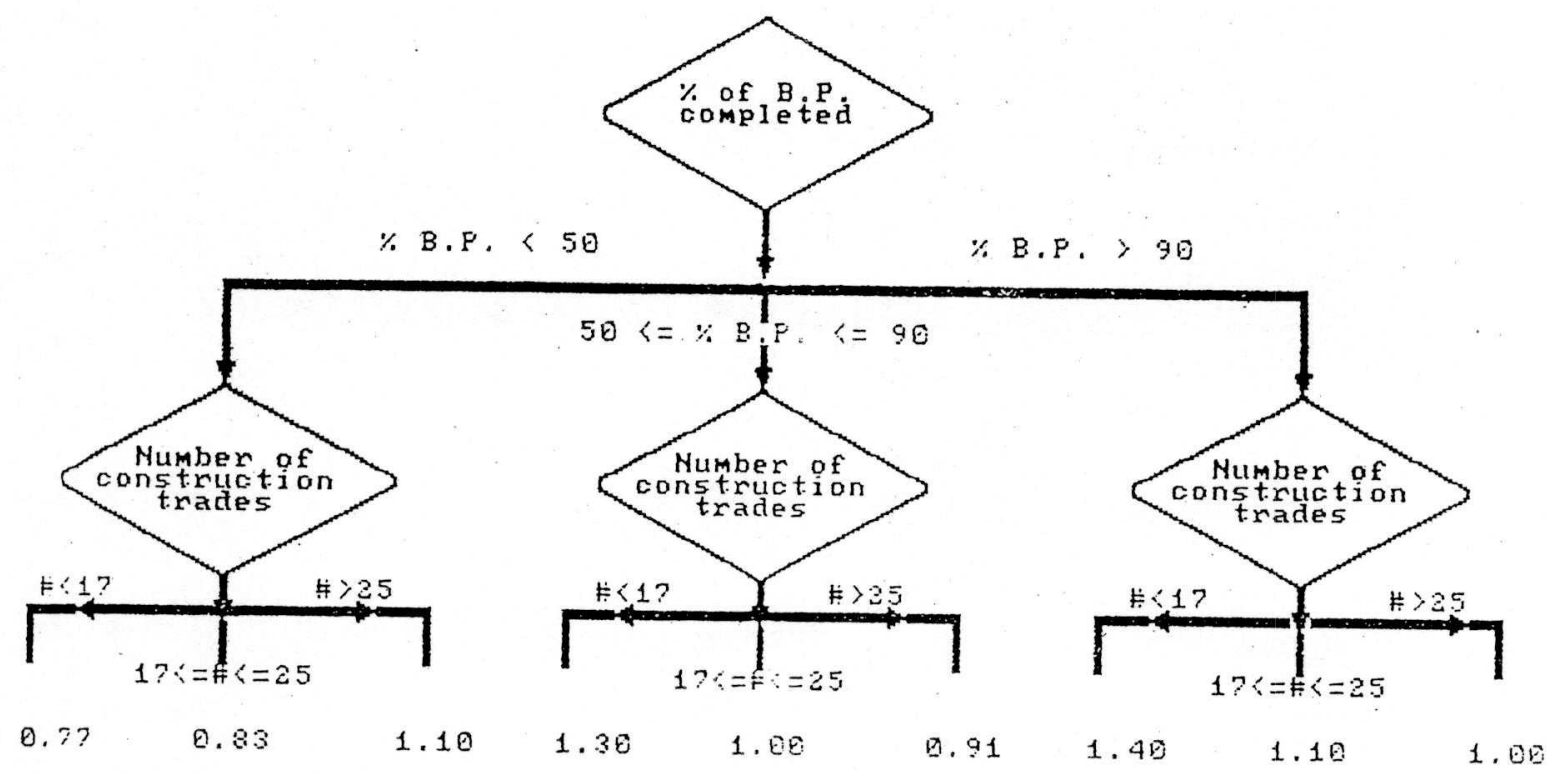

where: $\%$ of B.P. completed = Percentage of blue prints completed before beginning of construction.

$\because=$ Number of construction trades.

P.M. = Project multiplier.

Fig 2:Reasoning scheme for determination of project multiplier. 